\title{
Dynamic Characteristics of Submerged Floating Tunnel Under Irregular Waves
}

\author{
Naik Muhammad, Saeedullah Jan Mandokhail, Muhammad Habib, Zafar Baloch, Azmat Ullah \\ Khan \\ Department of Civil Engineering, Faculty of Engineering and Architecture, Balochistan University of \\ Information Technology, Engineering and Management Sciences, Quetta, Pakistan.
}

\begin{abstract}
SFT) is an innovative structural solution for waterway crossings and is based on the idea of Archimedes Buoyancy. The main structure is kept at a certain depth underwater and is placed in position by anchor/mooring cables. SFT becomes a more economical alternative for waterways compared to classical solutions such as cable-supported bridge, immersed tunnel or underground tunnel when the width and depth of the waterway are large enough. As SFT is completely submerged in water and is subjected to extreme environmental conditions such as waves, earthquakes, and hurricanes, therefore, the evaluation the dynamic characteristics of an SFT under irregular waves is a key demand from the design point of view. In this study, the responses of an SFT that is to be built in Qindao Lake of China are investigated under irregular waves. A 3D FEM model for SFT was established, the tunnel was modeled by 3D beam elements and cables were modeled by elastic catenary elements. The irregular waves were modeled by JONSWAP spectrum. The time history analysis was performed under irregular waves and currents. The time-domain simulations were transformed to the frequency domain by Fast Fourier Transform (FFT). The spectra were smoothed using Savitzky-Golay smoothing filters. The transfer functions of SFT horizontal and vertical displacements; and cable tensions were obtained for 30 realizations. Two major peaks have been observed in each transfer function (response spectrum). One of the peaks was associated with the peak wave frequency; the second peak was associated with the translational natural frequency of the SFT.
\end{abstract}

Keywords- Submerged floating tunnel (SFT), dynamic characteristics, Irregular waves, spectrum, and Transfer functions

Date Received 02-09-2019

Date Accepted 25-12-2019

Date Published 31-12-2019

\section{INTRODUCTION}

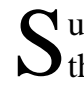
ubmerged floating tunnel (SFT) is a massive structure and the structural behavior is greatly influenced by waves and currents. A numerical procedure for the analysis of SFT accounting for seismic excitation was developed by Fogazzi $e t$ al. [1], however, more attention in this study was devoted to the 'ad hoc' finite element for modeling the behavior of anchor/mooring element accounting for geometrical nonlinearities and wave loading. A procedure for the nonlinear dynamic analysis of SFT considering 3D multi-support seismic excitations and nonlinear drag forces due to steady current and wind waves, was presented by Di Pilato et al. [2], however more focus in this research was to improve the finite element modeling of the anchor bars developed in the previous work. This work related to finite element development of anchor bars was improved and the dynamic behavior of SFT was evaluated using spatially varying seismic motion by Di Pilato et al. [3]. The structural analysis of SFT prototype to be built in Qindao Lake (PR of China) under environmental loads such as waves , currents and earthquakes was presented by [4] using commercial finite element tool ABAQUS. A more enhanced numerical procedure for the analysis of SFT considering spatial variability of seismic excitations was developed by [5]. A recent study that describes the spatial variation of ground motion excitation is carried by [6], this study also concluded that $2 \mathrm{D}$ and $3 \mathrm{D}$ fluid fields have a great impact on the magnitude of displacements of SFT along the tunnel length. Since SFT is a very large structure and the transient response analysis requires a large amount of computational space, therefore, the model order reduction is necessary for the design process of SFT. A model order reduction procedure was applied to solve the transient responses of SFT model to be built from Mokpo to Jeju (South Korea) under seismic excitations by [7]. The effect of seismic excitation on the response of SFT could be different as compared to other civil engineering structures on the ground. The effects of seawater on seismic behaviors on SFT considering the compressibility if seawater, was studied by [8] using a rectangular SFT.

Submerged floating tunnel (SFT) is a fully submerged structure and exposed to severe environmental conditions. Two approaches are normally used in choosing the design wave environment for an offshore structure. One of these uses a single wave method in which the design wave is represented by a wave period and wave height [9], this approach is referred to as regular waves. Due to its simplicity, most of the literature considers the response of SFT under this approach. 
The other approach is to select the design wave environment considering the wave spectrum; this approach is commonly referred to as irregular waves. The offshore oil and gas industry use floating structures for production systems, such as floating spars, Tension Leg Platforms (TLPs), semi-submersible platforms, and the Floating, Production, Storage, and Offloading systems (FPSOs). These floating structures are moored by mooring cables to maintain their positions. The dynamic response of these structures under irregular waves have been widely studied and reported [10-12]. However, the response of SFT under irregular waves could be very important due to the extreme exposure of SFT to sea waves. A very primary attempt by a recent study [13] in this regard is available as a reference. This paper perform a parametric study of the responses of SFT under irregular waves.

The aim of this study is to investigate the SFT response under irregular waves. The JONSWAP spectrum is used to model the random sea waves. The airy wave theory is used to evaluate the wave forces. The time-domain solution of 30 realizations has been used to obtain the SFT response. The response spectrums are obtained by using the Fast Fourier transform (FFT). The spectrums are filtered (smoothed) using Savitzky-Golay smoothing filters $[11,14]$.

\section{MODELING OF WAVES}

The ocean waves and currents are random in nature due to the random nature of the wind that causes to generate these waves. The growth of the sea depends on the wind speed, duration and fetch [9]. Many spectrums have been developed for forecasting the wind-generated waves. The suitable representation of the sea state or more precisely the wave loading is the primary concern. Once the wave conditions are evaluated, the wave loading on the SFT may be computed based on suitable wave theory. As the SFT case studies are mostly located in narrow seas, therefore, the sea state may be considered to be partially developed. In this study, the JONSWAP spectrum is used, which is more suitable to represent the partially developed sea state. The wave loadings are then evaluated using the Airy wave theory.

The JONSWAP spectrum is based on two representing parameters namely significant wave height $\left(H_{\mathrm{s}}\right)$ and peak wave period $\left(T_{\mathrm{p}}\right)$. The spectrum describes the wave's energy distribution as a continues function of the frequency. This spectrum is given as

$S(f)=\frac{\alpha g^{2}}{(2 \pi)^{4} f^{5}} \exp \left[-\frac{5}{4}\left(\frac{f}{f_{p}}\right)^{-4}\right] \gamma^{\exp \left[-\frac{\left(f-f_{p}\right)}{2 \sigma^{2} f_{p}}\right]}$

where $f=\omega / 2 \pi=1 / T, f_{p}=1 / T_{p}, T_{p}$ is peak period, $\alpha(=0.0081)$ is a constant an depends on the wind, $\gamma$ is peakedness parameter ranging from 1 to 7 (mean 3.3), and $S(f)$ is energy spectrum and has a unit of "length ${ }^{2}$-time". $\sigma$ is shape parameter and is given as

$\sigma= \begin{cases}0.07 f & \leq f_{p} \\ 0.09 f & \geq f_{p}\end{cases}$
The sea surface elevation is taken to be the representative parameter of the sea state. In this study, the waves are assumed stationary. The generated random wave is considered to be adequately represented by a summation of linear harmonic regular waves. The series representation of sea surface elevation is given as $[9,15]$ :

$\eta(x, t)=\sum_{i=1}^{N} A_{i} \cos \left(x k_{i}-\omega_{i} t+\phi_{i}\right)$

Where

$A_{i}=\sqrt{2\left[S\left(\omega_{i}\right) \Delta \omega_{i}\right]}$

where $A_{i}$ is the amplitude of the $i^{\text {th }}$ component wave,

$\Delta \omega_{i}=\omega_{i}-\omega_{i-1}, \phi_{i}$ is random phase angle $[0$ to $2 \pi], \omega_{i}$ is

random wave frequency of the $i^{\text {th }}$ component wave, $k_{i}$ is wave number of the $i^{\text {th }}$ component wave. The selection of the frequency is performed by a random number generator in MATLAB in a range $\left[\begin{array}{ll}\omega_{i} & \omega_{n}\end{array}\right]$. A sampling frequency of 50 $\mathrm{Hz}$ is used for generating the random sea surface elevation ( $\eta$ ). For each time history 200 regular wave frequencies were chosen in the present study to make a single irregular wave.

Once random sea surface elevation $(\eta)$ (Eq. 3) is known the time histories of the wave-particle velocities and wave-particle accelerations are computed by wave superposition, according to Airy wave theory as [16]:

$\dot{u}=\sum_{i=1}^{N} A_{i} \omega_{i} \cos \left(X k_{i}-\omega_{i} t+\phi_{i}\right) \frac{\cosh \left[k_{i}(Z+h)\right]}{\sinh \left(k_{i}(h+\eta)\right)}$

$\dot{v}=\sum_{i=1}^{N} A_{i} \omega_{i} \sin \left(X k_{i}-\omega_{i} t+\phi_{i}\right) \frac{\sinh \left[k_{i}(Z+h)\right]}{\sinh \left(k_{i}(h+\eta)\right)}$

$\ddot{u}=\sum_{i=1}^{N} A_{i} \omega_{i}^{2} \sin \left(X k_{i}-\omega_{i} t+\phi_{i}\right) \frac{\cosh \left[k_{i}(Z+h)\right]}{\sinh \left(k_{i}(h+\eta)\right)}$

$\ddot{w}=\sum_{i=1}^{N} A_{i} \omega_{i}^{2} \cos \left(X k_{i}-\omega_{i} t+\phi_{i}\right) \frac{\sinh \left[k_{i}(Z+h)\right]}{\sinh \left(k_{i}(h+\eta)\right)}$

where parameter X, Y, Z, and $h$ are those described in [16].

Using the above wave-particle velocities and accelerations the wave forces are calculated by the modified Morison equation.

\section{EQUATIONS OF MOTION}

The equation of motion for the SFT for net buoyancy and random wave loads is given as [16]:

$[M]\{\ddot{q}\}+[C]\{\dot{q}\}+[K]\{q\}=\{f(q, t)\}$

where $\{f(q, t)\}$ is random wave loads generated based on the JONSWAP wave spectrum. Other parameters are those described in $[16,17]$. The mooring cables were modeled by the procedure described in $[16,18,19]$. The boundary conditions and limitations are similar to those described by [16]. 
The $47.56 \mathrm{~s}$ time-domain analysis was performed to study the response of SFT under random waves. The random responses were transformed to the frequency domain by applying Fast Fourier transformation. The spectra were smoothed by Savitzky-Golay smoothing filters [14], implemented in MATLAB functions. In the Savitzky-Golay smoothing filter, the polynomial order and the frame length were kept 5 and 15 respectively for all the spectra.

\section{NUMERICAL RESULTS}

The input parameters for the SFT tunnel, hydrodynamics, and mooring cables are the same as used in [16, 20] unless mentioned otherwise. A significant wave height $\left(H_{\mathrm{s}}\right)$ of $3 \mathrm{~m}$ and peak wave period $\left(T_{\mathrm{p}}\right)$ of $4 \mathrm{~s}$ are selected for the response calculation in this study. The responses of SFT are calculated for the structural model shown in Fig. 1. The pre-tensions in the cables have been calculated from the net buoyancy and are given in [16].
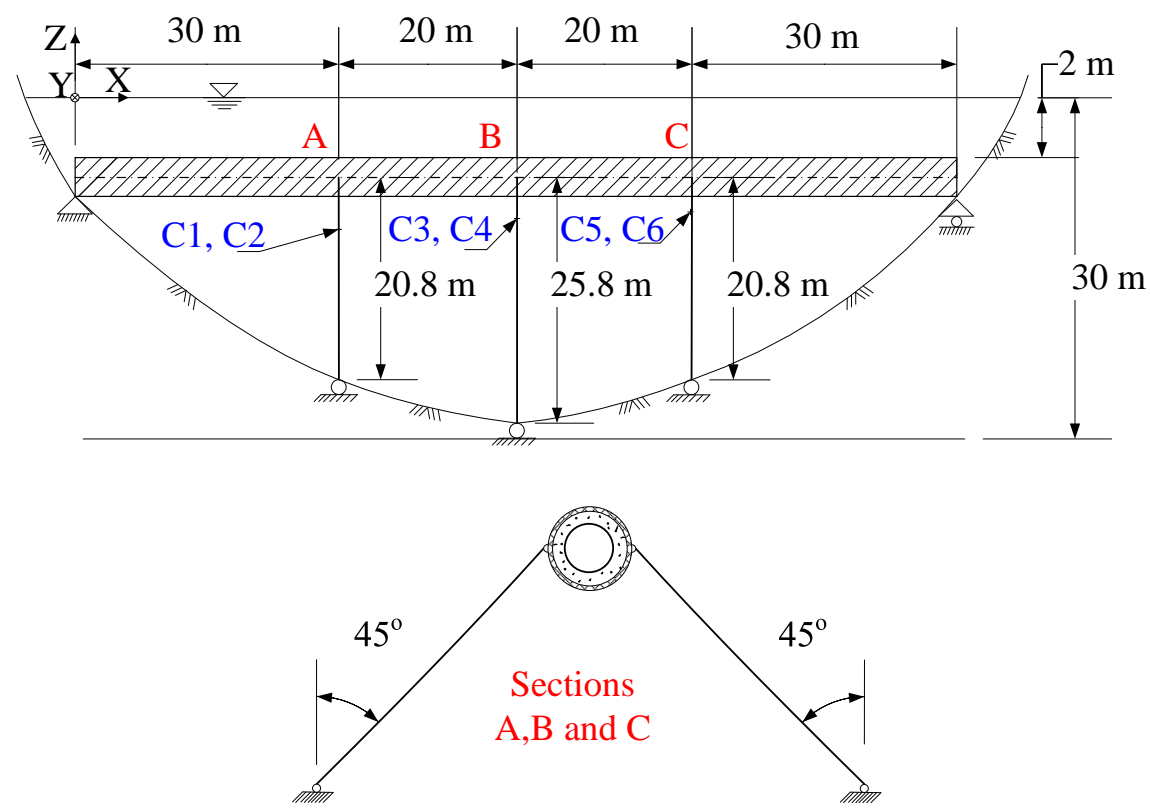

Fig. 1. Structural model of SFT used for numerical simulations [16, 21]

The JONSWAP spectrum Eq. (1) is calculated as shown in Fig. 2. The frequency $(\omega)$ was generated as a random number between 0 to $9 \mathrm{rad} / \mathrm{s}$. 200 regular waves were superimposed for the generation of each irregular wave.

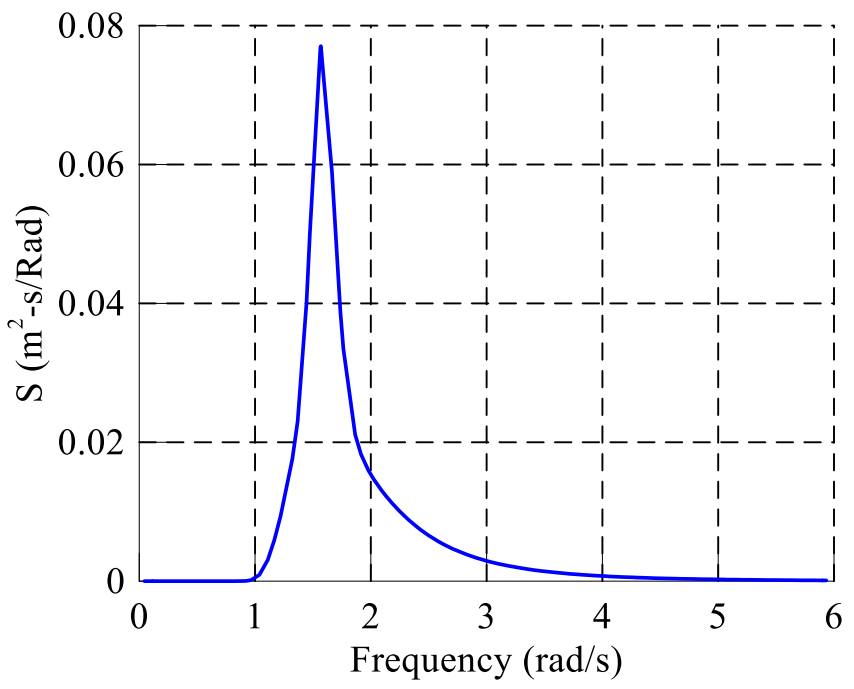

Fig. 2. JONSWAP spectrum $\left(\mathrm{H}_{\mathrm{s}}=3 \mathrm{~m}, \mathrm{~T}_{\mathrm{p}}=4 \mathrm{~s}\right)$

The wave surface elevation (Eq. (3)) is a representative parameter of the sea state. The time history of the wave surface elevation is shown in Fig. 3. The sampling frequency of $50 \mathrm{~Hz}$ (time step $0.02 \mathrm{~s}$ ) was used to generate this random sea surface elevation. As the wave surface elevation is based on the random frequency and random phase angles. Therefore, it is important to use an average response of the structure based serval realizations. In the present study, the dynamic analysis of SFT was performed 30 times based on 30 random sea surface elevations to obtain a suitable average random response of the SFT, which was then transformed by FFT to the frequency domain. 


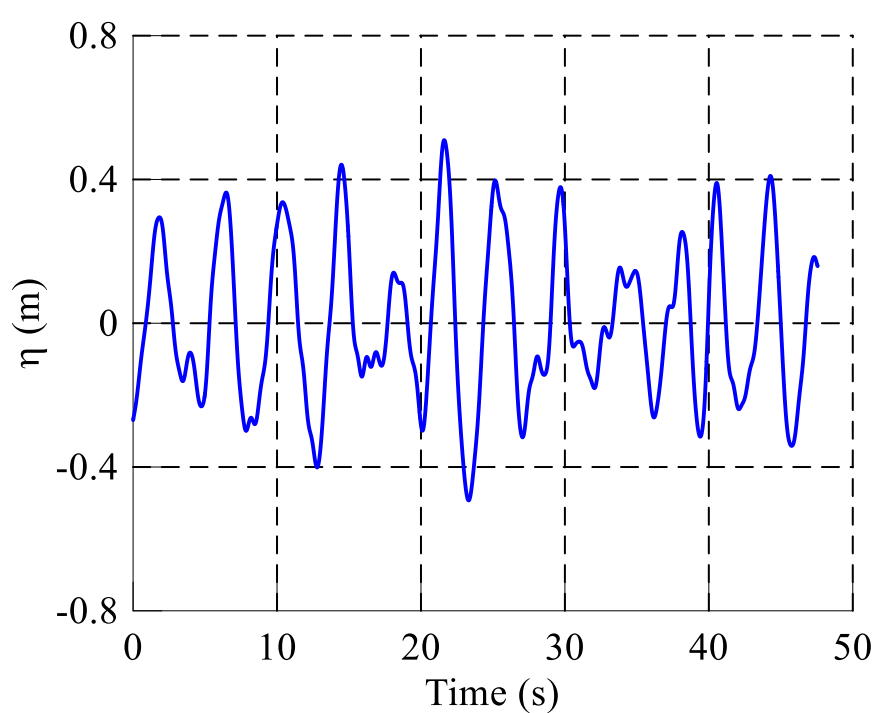

Fig. 3. Time history of the random wave surface elevation $\left(H_{s}=3 \mathrm{~m}, \mathrm{~T}_{\mathrm{p}}=4 \mathrm{~s}\right)$

In the time domain dynamic analysis, the duration and the time step must be carefully chosen. The time step must be small enough to capture the highest frequency of the load/response phenomena, and the duration should be long enough to capture the lowest frequency phenomena [22].

The SFT displacements and cable top tensions (average random responses of SFT based on 30 realizations of the dynamic analysis) time histories at location $\mathrm{A}$, under random waves, are shown in Fig. 4. The SFT undergoes very large horizontal displacement $\left(\mathrm{q}_{\mathrm{Y}}\right)$ and vertical displacements $\left(\mathrm{q}_{\mathrm{Z}}\right)$. Due to large SFT displacements, the mooring cables cause large tensions, and very large tension peaks can be seen in the cable top tension time histories as shown in Figs. 4(c,d).The top tension of the cable $1(\mathrm{C} 1)$, and cable $2(\mathrm{C} 2)$ show alternate peaks. When the tension in cables falls well below the pretension in cable 1 or cable $2\left(\mathrm{~T}_{0}=0.6187 \times 10^{6} \mathrm{~N}\right)$, and cable 3 or cable $4\left(\mathrm{~T}_{0}=0.4950 \times 10^{6} \mathrm{~N}\right)$, Then a slack condition happens. The transition from the slack to taut causes extreme tension in the cable which is also called snap tension [23]. This snap tension needs to be avoided for the practical design of SFT.

The SFT displacements and cable top tensions (average random responses of SFT based on 30 realizations of the dynamic analysis) time histories at location $\mathrm{B}$, under random waves, are shown in Fig. 5. The SFT undergoes very large horizontal displacements $\left(\mathrm{q}_{\mathrm{Y}}\right)$ and vertical displacements $\left(\mathrm{q}_{\mathrm{Z}}\right)$.

Due to large SFT displacements, the mooring cables operate in alternate taut-slack conditions and very large tension peaks can be seen in the cable top tension time histories as shown in Figs. $5(\mathrm{c}, \mathrm{d})$. 
Journal of Applied and Emerging Sciences Vol (09), Issue (02)
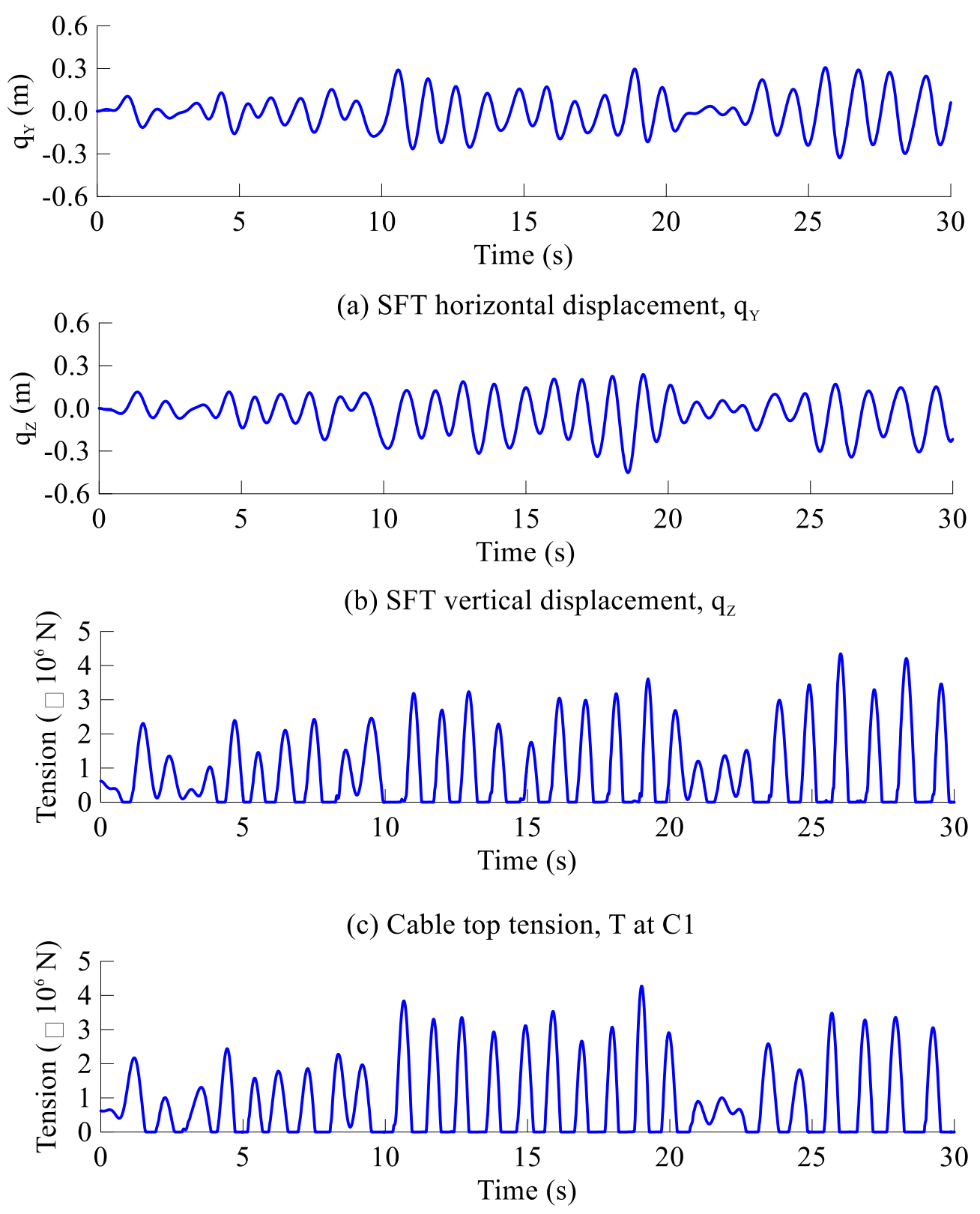

(d) Cable top tension, $\mathrm{T}$ at $\mathrm{C} 2$

Fig. 4. SFT displacements and cable top tension time histories at location A, under random waves $\left(\mathrm{H}_{\mathrm{s}}=3 \mathrm{~m}, \mathrm{~T}_{\mathrm{p}}=4 \mathrm{~s}, \zeta=2.5 \%\right)$ 


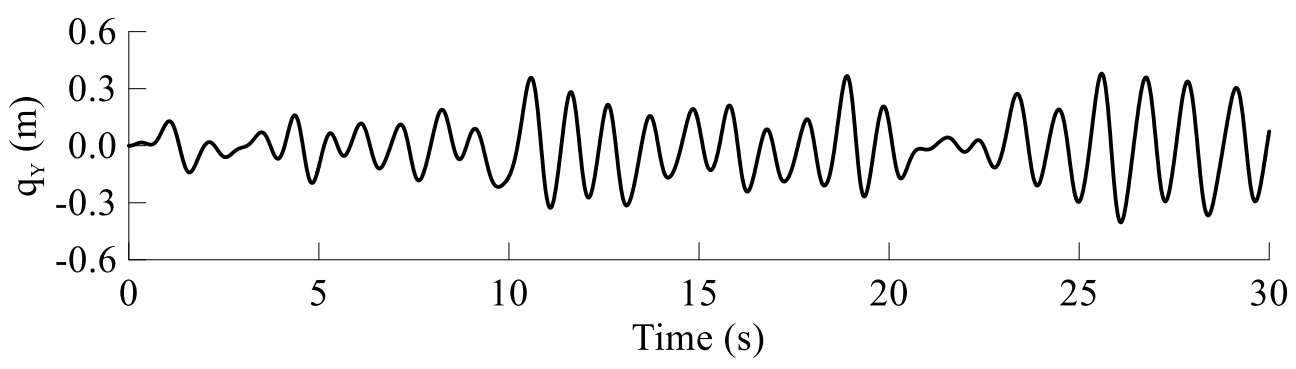

(a) SFT horizontal displacement, $\mathrm{q}_{\mathrm{Y}}$
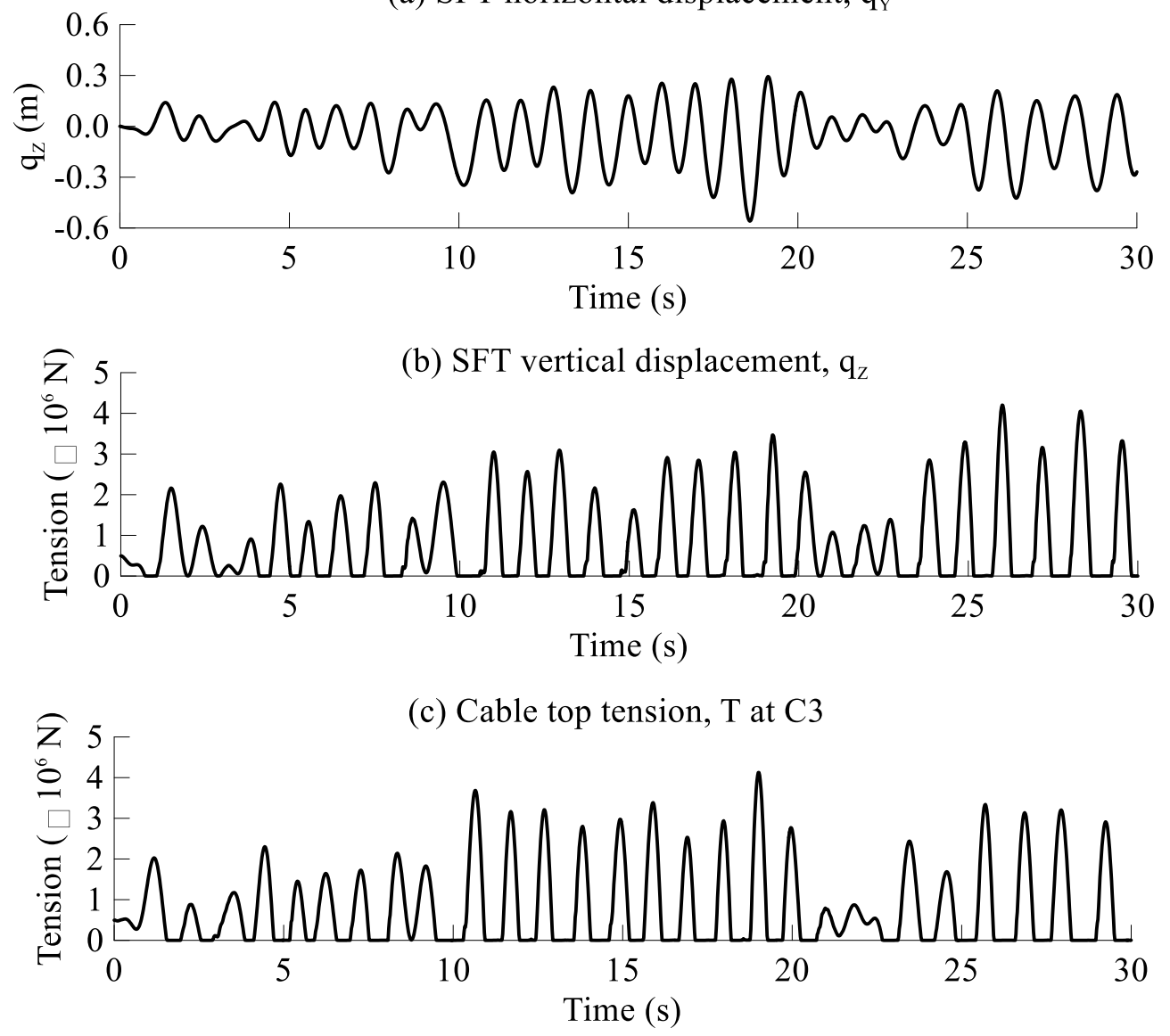

(d) Cable top tension, $\mathrm{T}$ at $\mathrm{C} 4$

Fig. 5. SFT displacements and cable top tension time histories at location $B$, under random waves $\left(H_{s}=3 \mathrm{~m}, \mathrm{~T}_{\mathrm{p}}=4 \mathrm{~s}, \zeta=2.5 \%\right)$

The smoothed SFT displacement and cable top tension spectra at location A are shown in Fig. 6. Two major peaks can be observed in each response spectrum. The frequencies at which the peaks occur can be associated with one of the frequency components that compose the dynamic behavior of the SFT. The major peaks can occur at wave frequency, structural natural frequency, sum (wave frequency + structural natural frequency) frequency, difference (structural natural frequency - wave frequency) frequency, double wave frequency, or double structural natural frequency [22].

The first component is induced by peak wave frequency. The second component is either due to the lateral and vertical motion of the SFT or sum/difference frequency. The peak wave frequency is $1.60 \mathrm{rad} / \mathrm{s}$ and the first natural structural frequency in the horizontal and vertical direction is $6.91 \mathrm{rad} / \mathrm{s}$. Many other minor peaks can be correlated to a frequency such as wave and natural structural frequency, sum-frequency, difference frequency or double wave frequency.

From the horizontal displacement $\left(\mathrm{q}_{\mathrm{Y}}\right)$ spectrum shown in Fig. 6(a), the first major peak occurring close to $1.60 \mathrm{rad} / \mathrm{s}$ corresponds to peak wave frequency (wave peak frequency is $1.6 \mathrm{rad} / \mathrm{s}$ ). The second major peak occurring at $5.55 \mathrm{rad} / \mathrm{s}$ close to the difference frequency $\left(\omega_{\text {structure }}-\omega_{\text {wave }}=5.31 \mathrm{rad} / \mathrm{s}\right)$. There are other minor peaks at $0.40 \mathrm{rad} / \mathrm{s}, 2.90 \mathrm{rad} / \mathrm{s}$, and $7.00 \mathrm{rad} / \mathrm{s}$. The last peak is close to the natural frequency of the structure. It is clear that wave and the difference frequency is causing the largest peak.

Similar trends exist in the spectrum of vertical displacement spectrum $\left(\mathrm{q}_{\mathrm{Z}}\right)$ as shown in Fig. 6(b) as described above. The first major peak occurring at $1.60 \mathrm{rad} / \mathrm{s}$ corresponds to peak wave frequency. The second major peak occurring at $6.0 \mathrm{rad} / \mathrm{s}$ may correspond to the structural frequency $(6.91 \mathrm{rad} / \mathrm{s})$. The 
frequency, which is close to the structural natural frequency, is causing the largest peak in the vertical displacement spectrum.

Figure 6 (c) describes the top tension spectrum of cable 1 (C1). Similar peaks can be observed as those for the displacements spectra. The first major peak occurring at 1.60 $\mathrm{rad} / \mathrm{s}$ corresponds to peak wave frequency. The second major peak occurring at $5.68 \mathrm{rad} / \mathrm{s}$ is close to the wave and structural difference frequency $\left(\omega_{\text {structure }}-\omega_{\text {wave }}=5.31 \mathrm{rad} / \mathrm{s}\right)$. Many other minor peaks can be seen that are associated with the sum frequencies or structural natural frequencies. The wave/structure difference frequency is causing the largest peak in the top tension spectrum of cable 1 .

Figure 6 (d) describes the top tension spectrum of cable 2 (C2). Similar peaks can be observed as those for the displacements spectra. The first major peak occurring at 1.60 $\mathrm{rad} / \mathrm{s}$ corresponds to peak wave frequency. The second major peak occurring at $5.81 \mathrm{rad} / \mathrm{s}$ is close to the natural structural frequency $\left(\omega_{\text {structure }}=6.91 \mathrm{rad} / \mathrm{s}\right)$. Many other minor peaks can be seen that are associated with the sum/difference frequencies or structural natural frequencies. The natural structural frequency is causing the largest peak in the tensions spectrum of cable 2 .

From the above discussion, it can be concluded that the SFT dynamic behavior is governed by natural structural frequency. The waves are the primary load to be considered for the design of SFT.

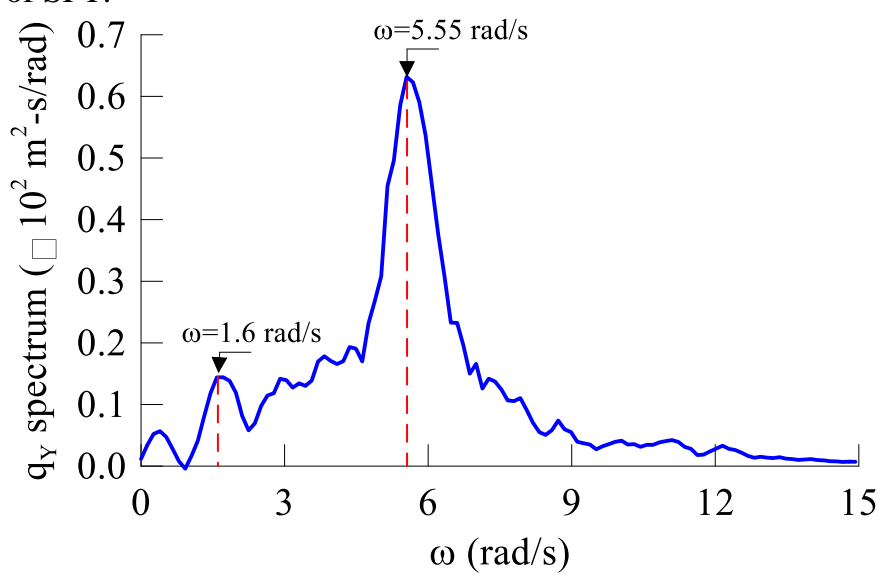

(a) SFT horizontal displacement, $\mathrm{q}_{\mathrm{Y}}$

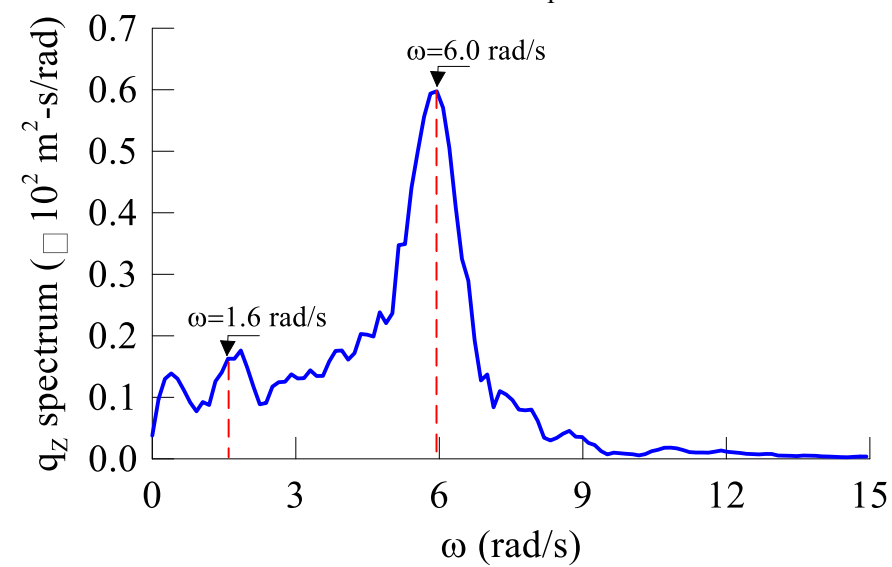

(b) SFT vertical displacement, $\mathrm{q}_{\mathrm{Z}}$

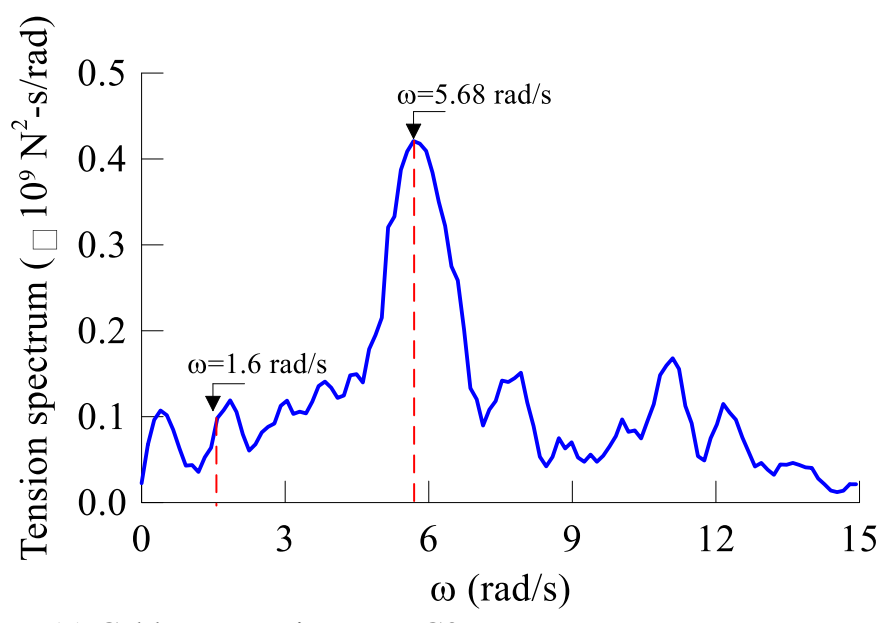

(c) Cable top tension, $\mathrm{T}$ at $\mathrm{C} 3$

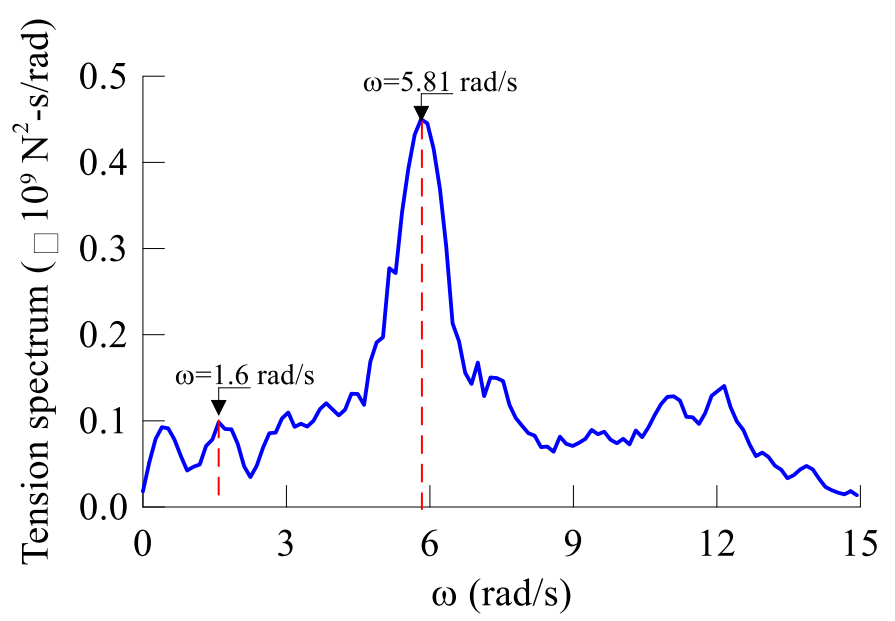

(d) Cable top tension, $\mathrm{T}$ at $\mathrm{C} 4$

Fig. 6. Smoothed SFT displacement and cable top tension spectra at location A $\left(\mathrm{H}_{\mathrm{s}}=3 \mathrm{~m}, \mathrm{~T}_{\mathrm{p}}=4 \mathrm{~s}, \zeta=2.5 \%\right)$

The Smoothed SFT displacement and cable top tension spectra at location B are shown in Fig. 7. The SFT displacement spectra follow the same trends and peaks as described for location A, with slightly larger responses here. The cable top tensions spectra at location B exactly match the spectra at location A. The peaks description and the conclusion drawn from the spectra at A is same for the spectra at B.

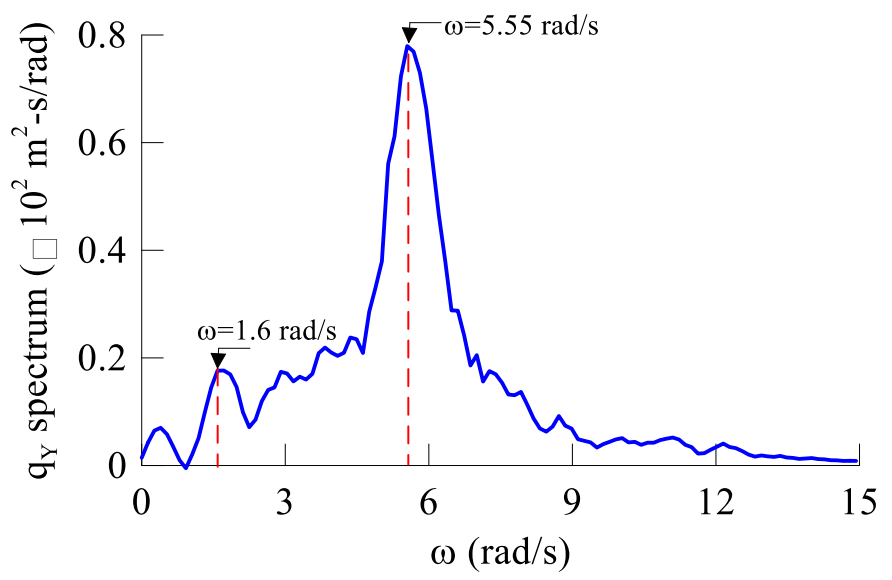

(a) SFT horizontal displacement, $\mathrm{q}_{\mathrm{Y}}$ 


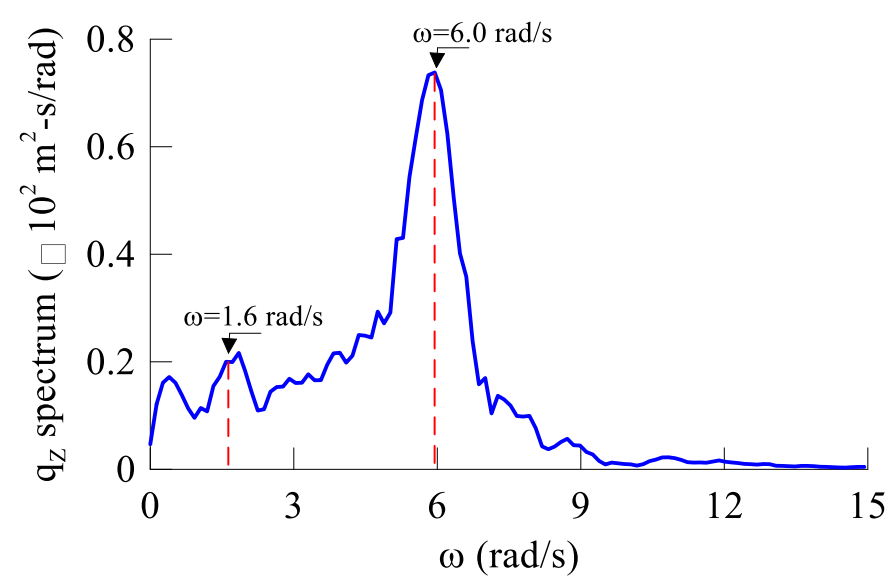

(b) SFT vertical displacement, $\mathrm{q}_{\mathrm{Z}}$

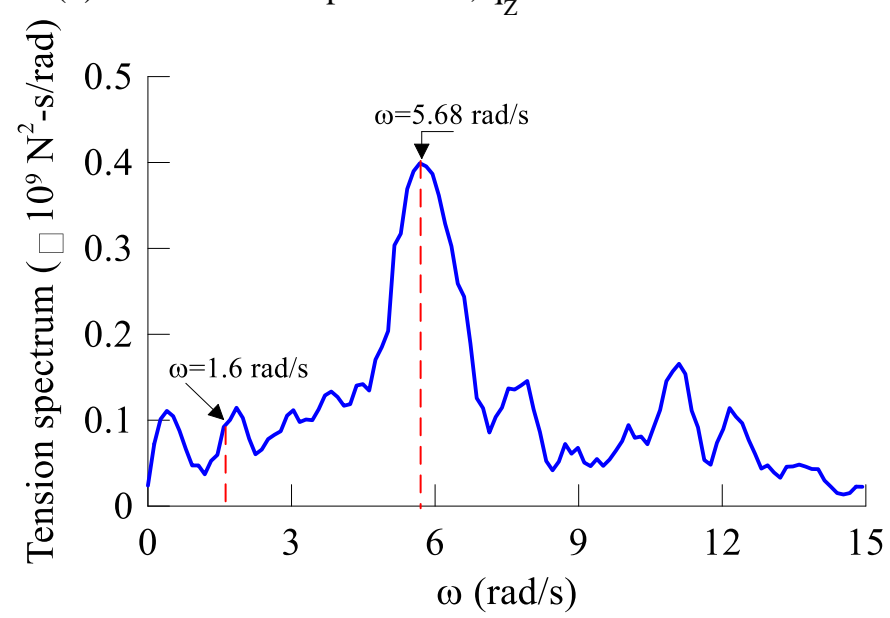

(c) Cable top tension, $\mathrm{T}$ at $\mathrm{C} 3$

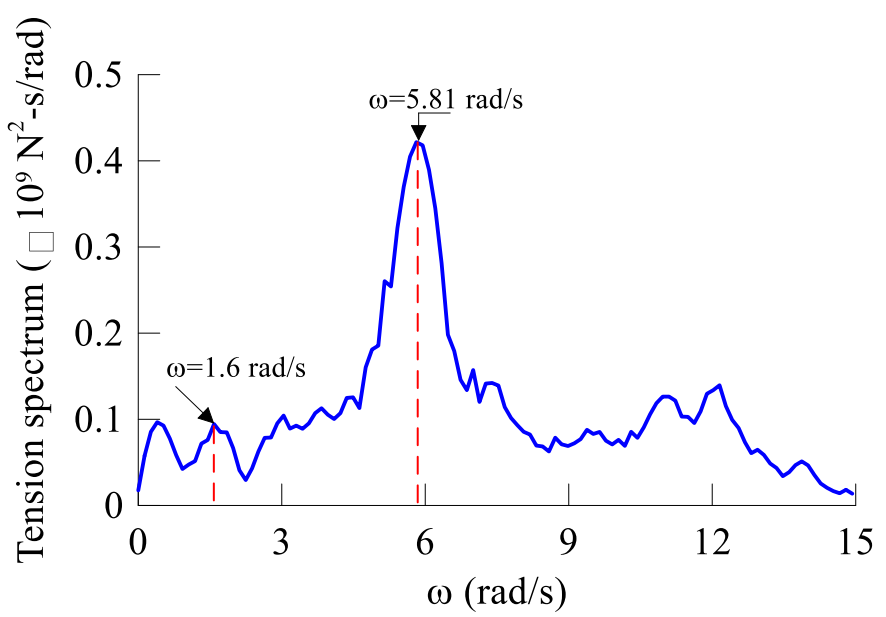

(d) Cable top tension, $\mathrm{T}$ at $\mathrm{C} 4$

Fig. 7. Smoothed SFT displacement and cable top tension spectra at location B $\left(\mathrm{H}_{\mathrm{s}}=3 \mathrm{~m}, \mathrm{~T}_{\mathrm{p}}=4 \mathrm{~s}, \zeta=2.5 \%\right)$

\section{CONCLUSIONS}

In this chapter, the response of SFT under irregular waves is investigated. The irregular waves were modeled by the JONSWAP spectrum. The time-domain simulations were transformed to the frequency domain by Fast Fourier Transform (FFT). The spectra were smoothed using Savitzky-Golay smoothing filters.

The spectrums of horizontal, vertical displacements and cable top tensions are evaluated at the locations A and B. similar peaks were observed in most of the results.

Based on the numerical simulations the following conclusion can be drawn:

(1) Two major peaks have been observed in each transfer function (response spectrum). One of the peaks is associated with the peak wave frequency; the second peak is associated with the translational natural frequency of the SFT.

(2) For a high wave frequency range, the structural natural frequency mainly governs the SFT response and major peak occurs close to the translational frequency of SFT.

(3) For a low wave frequency range, the wave frequency mainly governs the SFT response and major peak occurs close to the wave frequency.

\section{ACKNOWLEDGMENT}

We acknowledge the Higher Education Commission (HEC) Pakistan, for financially supporting the first author with the fully-funded scholarship during the study period of this research.

\section{REFERENCES}

P. Fogazzi and F. Perotti, "The dynamic response of seabed anchored floating tunnels under seismic excitation," Earthquake Engineering \& Structural Dynamics, vol. 29, pp. 273-295, 2000. M. Di Pilato, F. Perotti, and P. Fogazzi, "3D dynamic response of submerged floating tunnels under seismic and hydrodynamic excitation," Engineering Structures, vol. 30, pp. 268-281, 1// 2008. M. Di Pilato, A. Feriani, and F. Perotti, "Numerical models for the dynamic response of submerged floating tunnels under seismic loading," Earthquake Engineering \& Structural Dynamics, vol. 37, pp. 1203-1222, 2008.

F. Mazzolani, R. Landolfo, B. Faggiano, M. Esposto, F. Perotti, and G. Barbella, "Structural analyses of the submerged floating tunnel prototype in Qiandao Lake (PR of China)," Advances in structural engineering, vol. 11, pp. 439-454, 2008.

L. Martinelli, G. Barbella, and A. Feriani, "A numerical procedure for simulating the multi-support seismic response of submerged floating tunnels anchored by cables," Engineering Structures, vol. 33, pp. 2850-2860, 2011.

J. Mirzapour, M. Shahmardani, and S. Tariverdilo, "Seismic response of submerged floating tunnel under support excitation," Ships and Offshore Structures, pp. 1-8, 2016.

J. S. Han, B. Won, W.-S. Park, and J. H. Ko, "Transient response analysis by model order reduction of a Mokpo-Jeju submerged floating tunnel under seismic excitations," Structural Engineering and Mechanics, vol. 57, pp. 921-936, 2016.

J. H. Lee, S. I. Seo, and H. S. Mun, "Seismic behaviors of a floating submerged tunnel with a rectangular cross-section," Ocean Engineering, vol. 127, pp. 32-47, 11/15/ 2016.

S. K. Chakrabarti, Hydrodynamics of offshore structures: WIT press, 1987.

A. K. Agarwal and A. K. Jain, "Nonlinear coupled dynamic response of offshore Spar platforms under regular sea waves," Ocean Engineering, vol. 30, pp. 517-551, 3// 2003.

M. Yang, B. Teng, L. Xiao, D. Ning, Z. Shi, and Y. Qu, "Full timedomain nonlinear coupled dynamic analysis of a truss spar and its mooring/riser system in irregular wave," Science China Physics, Mechanics and Astronomy, vol. 57, pp. 152-165, 2014/01/01 2014. M. H. Kim, Z. Ran, and W. Zheng, "Hull/Mooring Coupled Dynamic Analysis of a Truss Spar In Time Domain," 2001/3/1/ 2001.
K. Seungjun and W. Deokhee, "Hydrodynamic analysis of the submerged floating tunnels under irregular waves " presented at the 
39th IABSE Symposium-Engineering the Future Vancour, Canada 2017.

[14] S. J. Orfanidis, Introduction to signal processing: Prentice-Hall, Inc., 1995.

[15] S. Chandrasekaran and A. K. Jain, "Triangular configuration tension leg platform behaviour under random sea wave loads," Ocean Engineering, vol. 29, pp. 1895-1928, 2002/12/01/ 2002.

[16] N. Muhammad, "Dynamic Responses of Submerged Floating Tunnels with Mooring Cables under Waves, Earthquakes, and Moving Loads," Ph.D. Thesis, Civil and Environmental Engineering Hanyang University Seoul, South Korea 2019.

[17] N. Muhammad, Z. Ullah, M.-W. Park, and D.-H. Choi, "The role of cable stiffness in the dynamic behaviours of submerged floating tunnel," MATEC Web Conf., vol. 138, // 2017.

[18] N. Muhammad, Z. Ullah, and D.-H. Choi, "A numerical procedure accounting for fluid drag forces and cable extensibility for the static response of mooring cables," International Journal of Steel Structures, vol. 18, pp. 293-303, March 012018.

[19] N. Muhammad, Z. Ullah, Z. Baloch, and D.-H. Choi, "Assessment of the Dynamic Behaviors of Submerged Floating Tunnel Under a High-Speed Train Loading," Oceanography \& Fisheries Open Access Journal vol. 10, pp. 1-15, 2019.

[20] N. Muhammad, Z. Ullah, and D.-H. Choi, "Performance evaluation of submerged floating tunnel subjected to hydrodynamic and seismic excitations," Applied Sciences, vol. 7, p. 1122, 2017.

[21] N. Muhammad, K. Azmatullah, Z. Baloch, H. Muhammad, and J. Saeed Ullah, "Effect of Cable Stiffness and Waves Parameters on the Dynamic Responses of Submerged Floating Tunnel," J. Appl. Emerg. Sci., vol. 8, pp. 152-159, 2018.

[22] M. Karimirad, Q. Meissonnier, Z. Gao, and T. Moan, "Hydroelastic code-to-code comparison for a tension leg spar-type floating wind turbine," Marine Structures, vol. 24, pp. 412-435, 2011/10/01/2011.

[23] W.-t. Hsu, K. P. Thiagarajan, and L. Manuel, "Extreme mooring tensions due to snap loads on a floating offshore wind turbine system," Marine Structures, vol. 55, pp. 182-199, 2017/09/01/ 2017.

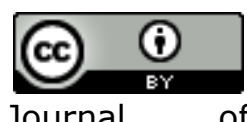

$$
\text { of Applied and Emerging }
$$

Sciences by BUITEMS is licensed under a Creative Commons Attribution 4.0 International License. 